\title{
Special Effect of Urea as a Stabilizer in Thermal Immersion Method to Synthesis Porous Zinc Oxide Nanostructures
}

\author{
F. S. Husairi, ${ }^{1,2}$ Syahirah Mhd Ali, ${ }^{1,2}$ A. Azlinda, ${ }^{1,2}$ M. Rusop, ${ }^{1,3}$ and S. Abdullah ${ }^{1,2}$ \\ ${ }^{1}$ NANO-SciTech Centre (NST), Institute of Science, Universiti Teknologi MARA (UiTM), 40450 Shah Alam, Selangor, Malaysia \\ ${ }^{2}$ Faculty of Applied Sciences, Universiti Teknologi MARA (UiTM), 40450 Shah Alam, Selangor, Malaysia \\ ${ }^{3}$ NANO-ElecTronic Centre (NET), Faculty of Electrical Engineering, Universiti Teknologi MARA (UiTM), \\ 40450 Shah Alam, Selangor, Malaysia
}

Correspondence should be addressed to F. S. Husairi; mhusairifadzilah@yahoo.com

Received 19 March 2013; Revised 28 June 2013; Accepted 1 July 2013

Academic Editor: Jinquan Wei

Copyright (C) 2013 F. S. Husairi et al. This is an open access article distributed under the Creative Commons Attribution License, which permits unrestricted use, distribution, and reproduction in any medium, provided the original work is properly cited.

\begin{abstract}
$\mathrm{ZnO}$ nanostructure was prepared by catalytic immersion method $\left(90^{\circ} \mathrm{C}\right)$ with zinc nitrate hexahydrate $\left(\mathrm{Zn}\left(\mathrm{NO}_{3}\right)_{2} 6 \mathrm{H}_{2} \mathrm{O}\right)$ as a precursors and urea $\left(\mathrm{CH}_{4} \mathrm{~N}_{2} \mathrm{O}\right)$ as a stabilizer. Different molarity concentration ratio of $\mathrm{Zn}\left(\mathrm{NO}_{3}\right)_{2} 6 \mathrm{H}_{2} \mathrm{O}$ to $\mathrm{CH}_{4} \mathrm{~N}_{2} \mathrm{O}, 2: 1,1: 4,1: 6$, and $1: 8$ is used in this work. The effect of urea concentration used during the synthesis process is discussed. The $\mathrm{ZnO}$ nanostructures were characterized by using field emission scanning electron microscope (FESEM), photoluminescene (PL), and $I-V$ probe. Porous nanoflakes are successfully synthesized on p-type silicon substrate coated with gold layer with different size and dimension. High intensity photoluminescence (PL) at optimum concentration indicated that urea is good stabilizer to produce $\mathrm{ZnO}$ nanostructures with good crytallinity. Rectifying characteristics show dramaticaly change in turn-on voltage when the concentration of urea increases in aqueous solution. This is related to the theory about p-type doping of $\mathrm{ZnO}$ nanostructures by nitrogen from $\mathrm{NH}_{3}$.
\end{abstract}

\section{Introduction}

$\mathrm{ZnO}$ posses unique characteristics because it is a semiconductor material with a direct band gap of $3.37 \mathrm{eV}$ and large excitation binding energy $(60 \mathrm{meV})$ which is important for near-ultraviolet emission and transparent conductivity. $\mathrm{ZnO}$ also is a piezoelectric material which suitable for sensor and tranducers application. Metal oxide semiconducting material becomes selecting device comparing solid state sensor due to small dimension, lower cost, low power consumption, simple processing, and stable. The conductivity of metal oxide semiconducting material can be improve by introducing a doping material. The impurity used to reduce the band gap of $\mathrm{TiO}_{2}$ and $\mathrm{N}^{-}$and $\mathrm{C}^{-}$dopand successfully narrow it [1]. Nitrogen is a good p-type dopant for II-VI semiconductors. Nitrogen dopant is used in metal oxide semiconductor to increase conductivity and produce $\mathrm{p}$-type conductor material because it more efficient than any other element since it contributes excess hole for conduction by forming an $\mathrm{N}-\mathrm{Zn}(\mathrm{O})-\mathrm{N}$ complex [2].
Differing from $\mathrm{ZnO}$, it is difficult to introduced $\mathrm{N}^{-}$in $\mathrm{ZnO}$ because $\mathrm{Zn}$ atoms always preferentially combine with $\mathrm{O}$, rather than with $\mathrm{N}$. Nitrogen has been known as suitable impurity for p-type doping in $\mathrm{ZnO}$. Based on theoretical study, incorporation of $\mathrm{N}$ in $\mathrm{ZnO}: \mathrm{N}$ can be improved if we increase the chemical potential in $\mathrm{N}$ source. From previous study, researcher used RF sputtering [3] technique, CVD method [4], spray pyrolysis [5], and so forth to dope $\mathrm{ZnO}$ with nitrogen. Most of them report that the conducting of $\mathrm{ZnO}$ increases by increasing concentration of $\mathrm{N}$ source. Asgrown $\mathrm{ZnO}$ typically has n-type conductivity with background concentrations between $10^{16}$ and $10^{17} \mathrm{~cm}^{-3}$ [4]. So, $\mathrm{N}^{-}$ is introduced in $\mathrm{ZnO}$ to increase the conductivity and change it into p-type conducting material.

In this paper, we report on the synthesis of $\mathrm{ZnO}: \mathrm{N}$ by using immersion method with varying molar concentration of urea in order to increase the source of $\mathrm{N}$. When urea dissolved in water, it will produce $\mathrm{CO}_{2}$ and ammonias $[6,7]$. This $\mathrm{CO}_{2}$ will form a carbonate ion $\left(\mathrm{CO}_{3}{ }^{2-}\right)$ which is used in $\mathrm{ZnO}$ formation, and ammonia molecules will supply the $\mathrm{N}$ 
atom [8]. Due to the much lower $\mathrm{N}-\mathrm{H}$ bonding energy in $\mathrm{NH}_{3}$, the decomposition of $\mathrm{NH}_{3} \mathrm{H}_{2} \mathrm{O}$ will become the main source for nitrogen in $\mathrm{ZnO}: \mathrm{N}$ formation. We found that when concentration of urea increases, the conductivity of $\mathrm{ZnO}$ film also increases and $\mathrm{N}_{2}$ response becomes more effective.

\section{Experimental}

In this work, zinc oxide nanostructures were grown by the catalytic immersion method using zinc nitrate hexahydrate $\left(\mathrm{Zn}\left(\mathrm{NO}_{3}\right)_{2} 6 \mathrm{H}_{2} \mathrm{O}\right)$ as a precursors and urea as a stabilizer. ptype silicon (100) as substrates was cut with the size that is $1.5 \mathrm{~cm} \times 2.0 \mathrm{~cm}$ and clean with acetone, methanol, and HF ( $48 \%$ HF : DI water $(1: 10))$. The silicon substrate was sputter coated with $6 \mathrm{~nm}$ thickness of gold $(\mathrm{Au})$ as a catalyst in argon plasma.

2.1. Synthesis of $\mathrm{ZnO}$ Nanostructures. For solution preparation, the molar ratio of the Zinc Nitrate Hexahydrate $\left[\mathrm{Zn}\left(\mathrm{NO}_{3}\right)_{2} 6 \mathrm{H}_{2} \mathrm{O}\right]$ to urea $\left[\mathrm{CH}_{4} \mathrm{~N}_{2} \mathrm{O}\right]$ in $100 \mathrm{~mL}$ was varied with ratio $2: 1,1: 4,1: 6$, and $1: 8$. The aqueous solution stirred and heated at $60^{\circ} \mathrm{C}$ for 1 hour and follow by the ageing process for 24 hours to produce homogenous solution. After the ageing process, the silicon substrate inserted into test tube filled with $40 \mathrm{~mL}$ of the solutions of different molar ratio concentration. Then the test tubes were immersed in a water bath at temperature of $90^{\circ} \mathrm{C}$. After 4 hours, samples were dried in 1 hour at temperature $150^{\circ} \mathrm{C}$ and were annealed at temperature $500^{\circ} \mathrm{C}$ for 1 hour. The morphology of the $\mathrm{ZnO}$ nanostructures was analyzed by Field Emission Scanning Electron Microscopy (JSM-7600F, FESEM). The optical properties are characterized by photoluminescence (HORIBA JOBIN YVON, PL) spectra at room temperature.

2.2. I-V Characteristics and $\mathrm{N}_{2}$ Response Studies. ZnO nanostructures were characterized by $I-V$ characteristic to measure electrical properties and $\mathrm{N}_{2}$ gas response. Gold layer (as a metal) with thickness $6 \mathrm{~nm}$ was coated on $\mathrm{ZnO}$ nanostructures by using sputtering technique like in Figure 1. $\mathrm{ZnO}$ nanostructures were placed in tight box with inlet and outlet for $\mathrm{N}_{2}$ gases. The current-voltage characteristics of $\mathrm{ZnO}$ nanostructures in vacuum and presence $\mathrm{N}_{2}$ gas were measured by Keithely 2400 multimeter and voltage source.

\section{Result and Discussion}

3.1. Chemical Decomposition in Thermal Immersion Method. The particle nucleation involves two steps, nucleation and growth with the nucleation rate needs to be faster than growth rate. Growth rate that depends on the amount of reacting particles available, while nucleation will take place after supersaturation is achieved, and this is affected by the solubility of the reacting particles [9]. Urea is highly soluble in water, and when urea which is one of amine groups dissolved in water, it will slowly displacement by water molucules to produce ammonia and carbonate anion

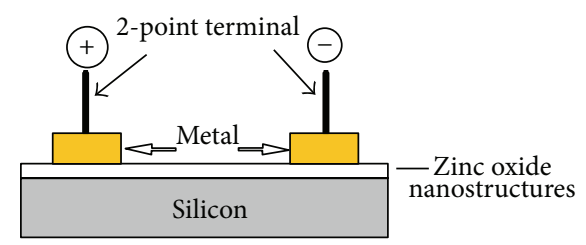

Figure 1: The schematic diagram of the electrodes plating on the surface of $\mathrm{ZnO}$ nanostructures.

$\left(\mathrm{CO}_{3}{ }^{2-}\right)$. The progression of chemical synthesis of $\mathrm{ZnO}$ in presence of urea is suggested as follows [6]:

$$
\mathrm{CON}_{2} \mathrm{H}_{4}+3 \mathrm{H}_{2} \mathrm{O} \longrightarrow \mathrm{CO}_{2}(\mathrm{~g})+2 \mathrm{NH}_{3} \mathrm{H}_{2} \mathrm{O}
$$

When temperatures increase, urea decomposed and produced $\mathrm{NH}_{3} . \mathrm{NH}_{4}^{+}$ions generated from $\mathrm{NH}_{3}$ ions will increase $\mathrm{pH}$ aqueous solution and support the $\mathrm{ZnO}$ crystal growth process:

$$
2 \mathrm{NH}_{3} \cdot \mathrm{H}_{2} \mathrm{O}+\mathrm{CO}_{2} \longrightarrow 2 \mathrm{NH}_{4}^{+}+\mathrm{CO}_{3}^{2-}+\mathrm{OH}^{-}
$$

Zinc nitrate hexahydrate will provide $\mathrm{Zn}^{2+}$ ions when dissolved in water as in

$$
\begin{gathered}
\mathrm{Zn}\left(\mathrm{NO}_{3}\right)_{2} \cdot 6 \mathrm{H}_{2} \mathrm{O}+\mathrm{H}_{2} \mathrm{O} \rightarrow \mathrm{Zn}^{2+}+2 \mathrm{NO}_{3}^{-}+7 \mathrm{H}_{2} \mathrm{O} \\
4 \mathrm{Zn}^{2+}+\mathrm{CO}_{3}{ }^{2-}+6 \mathrm{OH}^{-}+\mathrm{H}_{2} \mathrm{O} \\
\longrightarrow \mathrm{Zn}_{4} \mathrm{CO}_{3}(\mathrm{OH})_{6} \cdot \mathrm{H}_{2} \mathrm{O}(\mathrm{s}) \\
\mathrm{Zn}_{4} \mathrm{CO}_{3}(\mathrm{OH})_{6} \cdot \mathrm{H}_{2} \mathrm{O} \longrightarrow 4 \mathrm{ZnO}(\mathrm{s})+4 \mathrm{H}_{2} \mathrm{O}+\mathrm{CO}_{2}(\mathrm{~g})
\end{gathered}
$$

$\mathrm{Zn}_{4} \mathrm{CO}_{3}(\mathrm{OH})_{6} \cdot \mathrm{ZnO}$ is formed during the reaction in aqueous solution and after heating at $500^{\circ} \mathrm{C}$; it decomposed $\mathrm{ZnO}$ [10]. The degree of supersaturation of $\mathrm{Zn}(\mathrm{OH})_{2}$ in the interrfacial zone and the adsorption of organic/inorganic species on the surface of $\mathrm{ZnO}$ are the factors that can influence the nucleation and growth of $\mathrm{ZnO}$ nanostructures [11, 12].

3.2. Morphology of the Zinc Oxide Nanostructures. The presence of $\mathrm{Au}$ layer on Si substrate is a catalyst because it can provide an alternating energy pathway with lower activation energy. Heterogeneous nucleation promoted between $\mathrm{Au}$ particle and $\mathrm{Zn}$ and $\mathrm{O}$ ions is energetically favorable since the interfacial energy between the ions and adsorbed sites is lower. This is comparative to homogenous nucleation of two solid phases which has a higher activation energy barrier [13]. A large lattice match between $\mathrm{ZnO}$ nanostructures and $\mathrm{Si}$ is another factor of deposition of Au layer.

The morphology of $\mathrm{ZnO}$ nanostructures is observed by using Field Emission Scanning Electron Microscopy (JSM7600F, FESEM). Different molarity of solution had been contributed to the different size and morphology $\mathrm{ZnO}$ nanoconflakes structures. Figure 2 shows that the FESEM images of $\mathrm{ZnO}$ nanostructures had grown on the silicon substrate coated with $\mathrm{Au}$. As the urea concentration increases, the number of nanoflakes sheet also increases and their size reduced. At the lowest concentration of urea, the $\mathrm{ZnO}$ structures more to agglomerates structures and less sheet 


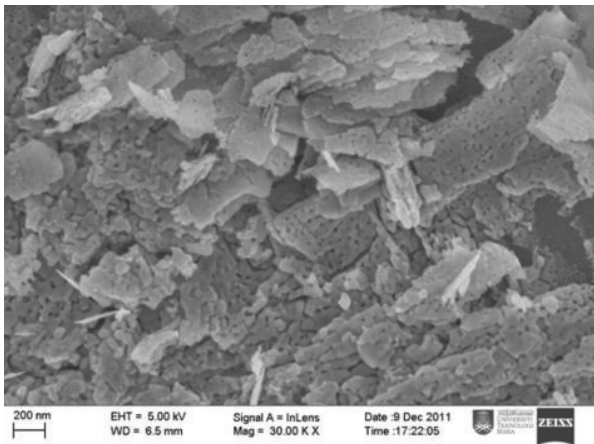

(a)

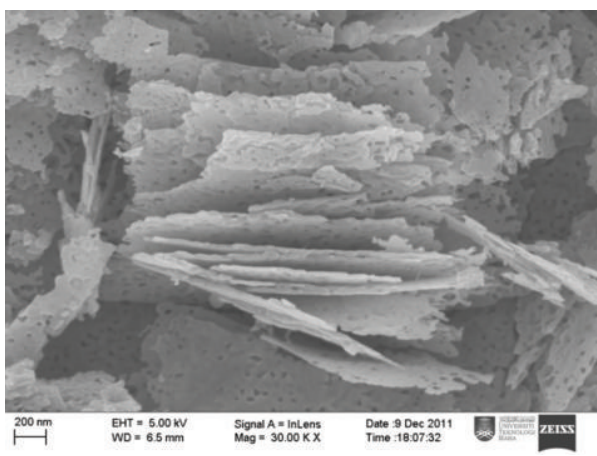

(c)

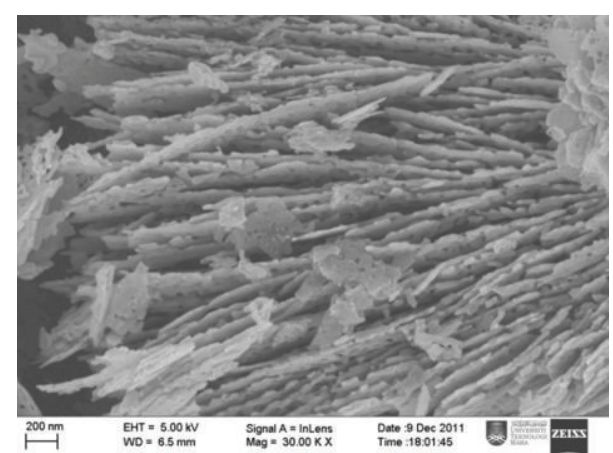

(b)

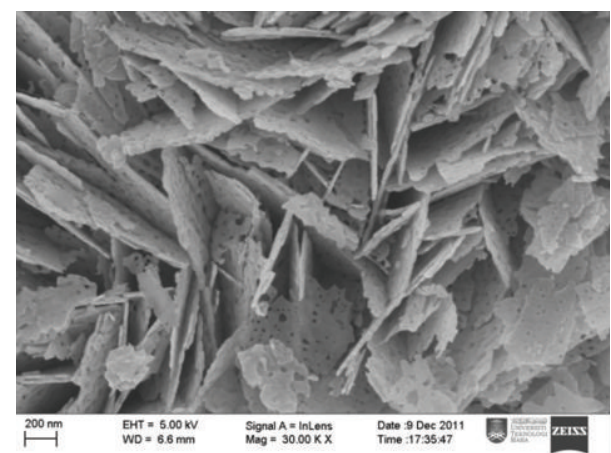

(d)

FIgURE 2: The FESEM micrographs of samples prepared at different concentration of $\mathrm{Zn}\left(\mathrm{NO}_{3}\right)_{2} \cdot 6 \mathrm{H}_{2} \mathrm{O}$ to urea in aqueous solution: (a) $0.02 \mathrm{M}: 0.01 \mathrm{M}$, (b) $0.01 \mathrm{M}: 0.04 \mathrm{M}$, (c) $0.02 \mathrm{M}: 0.06 \mathrm{M}$, and (d) $0.02 \mathrm{M}: 0.08 \mathrm{M}$.

structures form. It may be cause by less of number carbonate ions $\left(\mathrm{CO}_{3}{ }^{2-}\right)$ and $\mathrm{OH}^{-}$combine with $\mathrm{Zn}^{+}$to form crystalline $\mathrm{ZnO}$ nanostructures. For the sample $\mathrm{ZnO} 0.01 \mathrm{M}$ : Urea $0.04 \mathrm{M}$, the micrograph shows the early structures for $\mathrm{ZnO}$ before nanoflakes structures form. We can see that the primary nanoflakes structures with small size start to grow and no porous exists on it. From the observation on samples $\mathrm{ZnO} 0.01 \mathrm{M}$ : Urea $0.06 \mathrm{M}$ and $\mathrm{ZnO} 0.01 \mathrm{M}$ : Urea $0.08 \mathrm{M}$ as in Figures 2(c) and 2(d), the nanoflakes show a difference in the size and number as a concentration increase.

When concentration of urea (stabilizer) increases, the chance for $\mathrm{ZnO}$ nuclei to grow in their orientation is high. The probability of $\mathrm{ZnO}$ nuclei to agglomerate decreases and $\mathrm{ZnO}$ will form a large sheet number of nanoflakes. It can be deduced that smaller amount of $\mathrm{Zn}^{2+}$ ions leads to slower nucleation rate and induces smaller sheets growth. Too small a concentration may impede nuclei growth due to lack of starting material. The porous structures form on sheet flakes will increase the surface area that is good for sensing application.

3.3. Photoluminescence (PL) Spectra. Optical properties of $\mathrm{ZnO}$ nanostructures are being intensively studied for implementing photonic devices $\mathrm{ZnO}$-based material [14]. Figure 3 shows the PL spectrum of $\mathrm{ZnO}$ nanoflakes structures at varying stabilizer concentrations. Two emitting bands, including strong UV emission at $385-400 \mathrm{~nm}$ and weak orange band

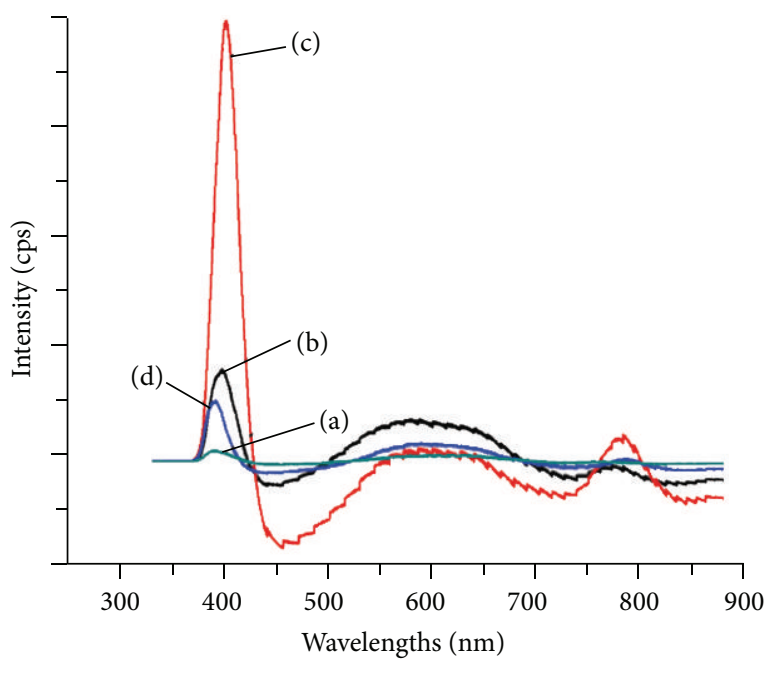
(a) $2: 1$
(c) $1: 6$
(b) $1: 4$
(d) $1: 8$

FIGURE 3: PL spectra of $\mathrm{ZnO}$ nanostructures at varying $\mathrm{Zn}^{2+}$ : Urea concentartion ratio: (a) $0.02 \mathrm{M}: 0.01 \mathrm{M}$, (b) $0.01 \mathrm{M}: 0.04 \mathrm{M}$, (c) $0.01 \mathrm{M}: 0.06 \mathrm{M}$, and (d) $0.01 \mathrm{M}: 0.08 \mathrm{M}$.

(585-620 nm), were observed. Peaks centered at ultra violet band-edge attributed to near band gap emission (NBE) and emission on visible range are due to the recombination of photogenerated holes with singly ionized charge states 
TABLE 1: Energy band gap ZnO nanostructures calculated based on photoluminescene (PL) spectra at UV emission.

\begin{tabular}{lcc}
\hline$\left(\mathrm{Zn}\left(\mathrm{NO}_{3}\right)_{2} \cdot 6 \mathrm{H}_{2} \mathrm{O}\right):\left(\mathrm{CH}_{4} \mathrm{~N}_{2} \mathrm{O}\right)$ & $\begin{array}{c}\text { Wavelength } \\
(\mathrm{nm})\end{array}$ & $\begin{array}{c}\text { Energy band } \\
\text { gap }(\mathrm{eV})\end{array}$ \\
\hline (a) $0.02 \mathrm{M}: 0.01 \mathrm{M}$ & 387 & 3.21 \\
(b) $0.01 \mathrm{M}: 0.04 \mathrm{M}$ & 395 & 3.20 \\
(c) $0.01 \mathrm{M}: 0.06 \mathrm{M}$ & 399 & 3.11 \\
(d) $0.01 \mathrm{M}: 0.08 \mathrm{M}$ & 390 & 3.19 \\
\hline
\end{tabular}

in intrinsic defects likes oxygen vacancies $\left(V_{\mathrm{O}}\right)$ and zinc interstitial $\left(\mathrm{Zn}_{i}\right)[15,16]$.

The excitonic emission in the UV range (from 385 to $400 \mathrm{~nm}$ ) is an intrinsic property of the wurtzite $\mathrm{ZnO}$ nanostructures. It originates due to excitonic recombination where electrons come back after being excited to this energy level in band gap and associate with a hole to form a pair of exciton. It can be seen that the emission at $387 \mathrm{~nm}(3.21 \mathrm{eV})$ shifts to $399 \mathrm{~nm}(3.11 \mathrm{eV})$ for ZnO 0.01 M : Urea 0.06 M before shifted back to short wavelength (Table 1). Due to quantum confinement effect theory, the energy emission shifts to higher energy when the size of the nanostructures decreases [17]. Emission energy of this band edge emission (NBE) obeys an inverse dependence on the size of nanostructures because it tale with FESEM result which nanoflake increase until optimum ratio (1 to 6) before reduced back. Besides, the shift of the exciton band to lower energy may be attributed to increase the carrier concentration closed to the valence band in the band gap [18] and the reducing of band gap [19]. When concentration of stabilizer increases (precursor concentration constant), the intensity of UV emission also increases until lowest energy, $3.11 \mathrm{eV}$. That means that the crystalline properties of the films improved and the intrinsic donor defects, such as $V_{\mathrm{O}}$ and $\mathrm{Zn}_{i}$, decreased [16]. At low urea concentration (less number of $\mathrm{N}$ atom), the formation of $\mathrm{ZnO}: \mathrm{N}$ is lower. This will produce the structural defect because of deficiency of oxygen to form the correct $\mathrm{ZnO}$ structures in the sample. The optimum stabilizer ratio was found at $0.01 \mathrm{M}$ of precursor to $0.06 \mathrm{M}$ because the intensity UV emission produced is higher compared to others.

The emission near the yellow region most probably is caused by two factors. Firstly, it can be caused by an excess of oxygen, and the presence of hydroxyl $(\mathrm{OH})$ group which found in $\mathrm{ZnO}$ was synthesized by using thermal immersion method [20,21]. The formation of interstitial oxygen ions is given by aqueous chemical growth because this is an oxygenrich growth method for $\mathrm{ZnO}$ [22]. Secondly, it may be due to presence of deep-level defect in $\mathrm{ZnO}$ nanostructure layer [23], where it can be reduced substantially by thermal treatment like annealing [24]. According to the PL spectra, $\mathrm{ZnO}$ grew at lowest stabilizer concentration $\left(\mathrm{CH}_{4} \mathrm{~N}_{2} \mathrm{O}\right)$ solution $\left(0.01 \mathrm{M}\right.$ with $0.02 \mathrm{M}$ of $\left.\mathrm{Zn}\left(\mathrm{NO}_{3}\right)_{2} \cdot \mathrm{H}_{2} \mathrm{O}\right)$, and a weak violet emission was observed.

3.4. I-V Characteristics of Zinc Oxide Nanostructures. The $I-V$ characteristic of $\mathrm{ZnO}$ nanostructures is measured by using 2-point probe in vacuum condition. Figure 4 shows

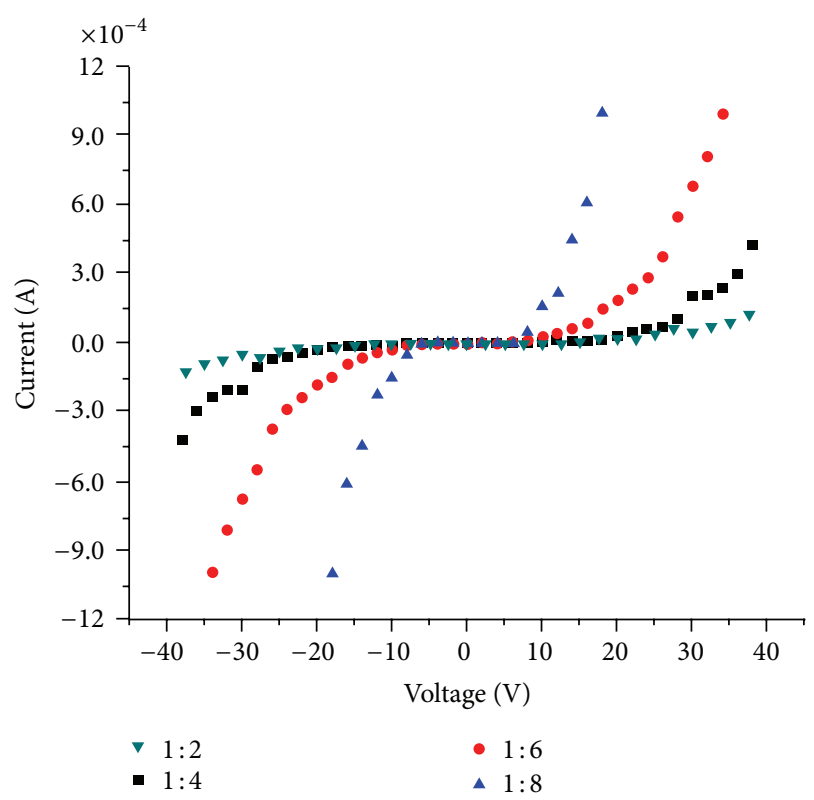

FIGURE 4: $I$ - $V$ characteristics of $\mathrm{ZnO}$ nanostructures with Au contact in air ambient.

the results of the $I-V$ measurements of $\mathrm{ZnO}$ deposited on p-Si substrate. Rectifying behavior is clearly illustrated for all samples produced but different in turn-on voltage value. Rectifying behavior for all samples existence because by the junction form at interface of $\mathrm{ZnO}$ film and $\mathrm{p}$-Si substrate [25]. $\mathrm{ZnO}$ exhibits $\mathrm{n}$-type semiconductors due to their dominant donor defects, such as oxygen vacancies and $\mathrm{Zn}$ interstitials [2]. The turn-on voltage decreases as the molar ratio of urea to zinc precursor increases. The observed values of turn-on voltage are $3.27 \mathrm{~V}, 2.79 \mathrm{~V}, 1.58 \mathrm{~V}$, and $1.42 \mathrm{~V}$ for $2: 1,1: 4,1: 6$, and $1: 8$, respectively. This negative trend is possible when the film is getting doped with "N." The decreasing of resistance can be related to two aspects: the first one reduced net compensation between holes and electrons due to reduction of oxygen vacancy, and the second one is doping of $\mathrm{N}$ into the lattice $[26,27]$.

Based on the theoretical study of the chemical trends in the defect energy levels by Kobayashi et al. [28], N would produce a shallow acceptor level in $\mathrm{ZnO}$ to form $\mathrm{ZnO}: \mathrm{N}$ form. This prediction made is based on the theoretical study of the chemical trends in the defect energy levels where the substitutional impurities are considered in a number of wurtzite-structured semiconductors. According to that finding, when the number of nitrogen in $\mathrm{ZnO}$ structures increases, the numbers of free carriers also increase. Beside, the introduction of "nitrogen" as a p-type dopant is more efficient than any other element due to formation of an $\mathrm{N}-\mathrm{Zn}(\mathrm{O})-\mathrm{N}$ complex and contributes excess "holes" for conduction [2].

Early, the sample may exhibit an n-type. As the $\mathrm{N}$ atom present in $\mathrm{ZnO}$ film increased, it will be activated as electron acceptors of the $\mathrm{ZnO}: \mathrm{N}$ thin film and turn to p-type $\mathrm{ZnO}$ behavior. Minimum turn-on voltage was observed at high concentration of urea, $\mathrm{ZnO} 0.01 \mathrm{M}$ : Urea $0.08 \mathrm{M}, 1.42 \mathrm{~V}$, so 


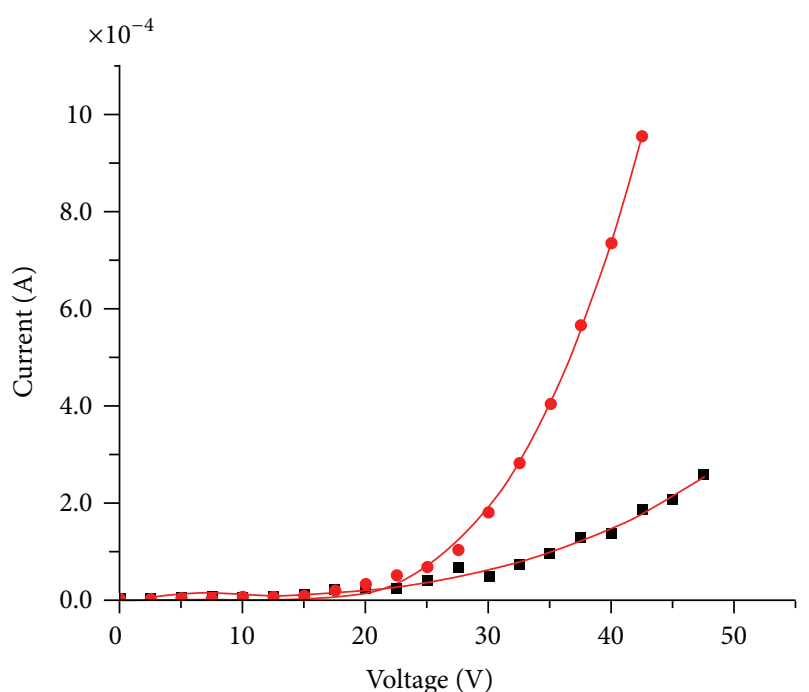

(a) ZnO $0.02 \mathrm{M}$ : Urea $0.01 \mathrm{M} 1.77 \mathrm{~V}$

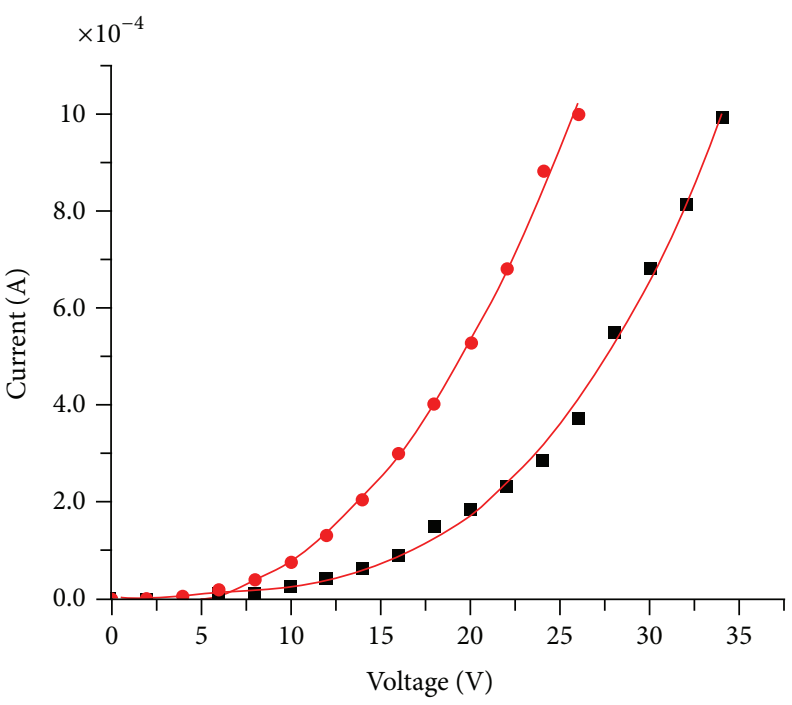

- In vacuum

- Present gas

(c) $\mathrm{ZnO} 0.01 \mathrm{M}$ : Urea $0.06 \mathrm{M} 1.0 \mathrm{~V}$

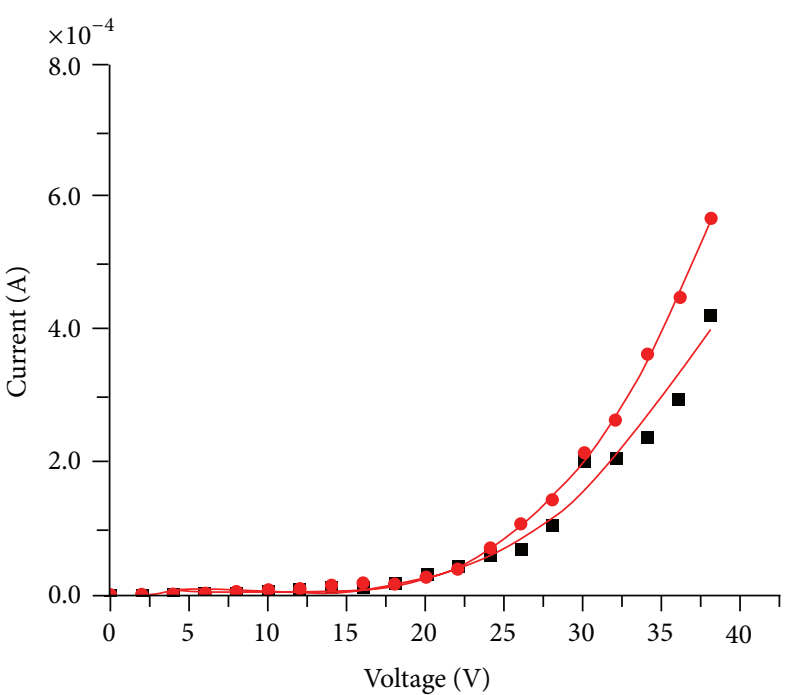

(b) $\mathrm{ZnO} 0.01 \mathrm{M}$ : Urea $0.04 \mathrm{M} 1.19 \mathrm{~V}$

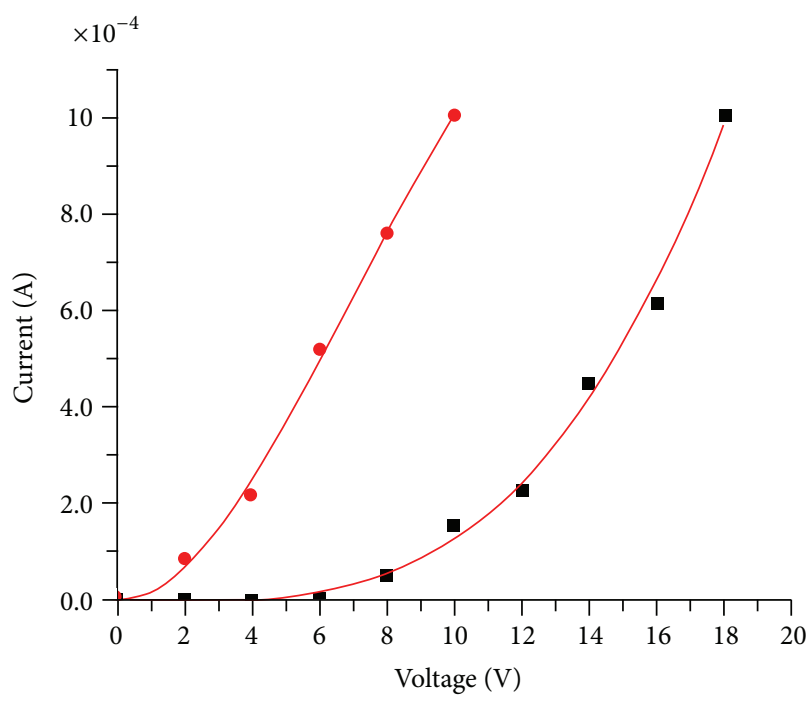

- In vacuum

- Present gas

(d) $\mathrm{ZnO} 0.01 \mathrm{M}$ : Urea $0.08 \mathrm{M} 0.2 \mathrm{~V}$

FIgURE 5: $I-V$ characteristics of $\mathrm{ZnO}$ nanostructures when exposed to $\mathrm{N}_{2}$ gas ambient.

the minimum operating potential for $\mathrm{ZnO}$ nanostructures as a based material because of increasing of oxidation and $\mathrm{N}$ dilution into $\mathrm{ZnO}$ lattice as a dopand. When the nitrogen atom in solution increased, the donor defects insufficient to compensate for the $\mathrm{N}$ substitutional acceptor and leads to an acceptor density increases. $\mathrm{N}$ atom that is present in $\mathrm{ZnO}$ film is activated as electrons acceptor of $\mathrm{ZnO}: \mathrm{N}$ thin film. More $\mathrm{N}$ atoms is present will lead to the further pronounced p-type $\mathrm{ZnO}$ behavior [25].

3.5. $\mathrm{N}_{2}$ Response of $\mathrm{ZnO}$ Nanoflakes Synthesized at Different Molar Concentration of Urea. Most of research in gas sensor were done more to gases which contain oxygen molecule and explained the response based of free electron on oxygen ions [29]. In this project, we test the $\mathrm{N}_{2}$ gas response by $\mathrm{ZnO}$ nanostructures which had a modification in term of conductivity (doping). Figure 5 shows the change of $I$ $V$ characteristics of $\mathrm{ZnO}$ nanostructures with variety of molarity of urea when exposed to $\mathrm{N}_{2}$ gas. From that figure, we can see that all the samples give a response to $\mathrm{N}_{2}$ gas in different sensitivity with good response detected at sample ZnO $0.01 \mathrm{M}$ : Urea $0.08 \mathrm{M}$.

Table 2 shows the changes of turn-on voltage and sensitivity of the samples when exposed to $\mathrm{N}_{2}$ gas. The detecting of chemical species usually determined by surface defect which may act as an active site to absorb the testing gas, and the ratio of area to volume [30]. The basis of the sensing mechanism for metal oxide is chemoresistivity, which changes in term of conductance or resistance when surface chemical reacts 
TABLE 2: Sensitivity of $\mathrm{ZnO}$ nanostructures prepared at different ratio concentration of $\mathrm{N}_{2}$ gas by $I-V$ characteristics of testing.

\begin{tabular}{|c|c|c|c|}
\hline \multirow{2}{*}{ Samples } & \multicolumn{2}{|c|}{ Turn-on volatge, $V_{\mathrm{O}}$} & \multirow{2}{*}{$\begin{array}{c}\text { Response, } S \\
S=\left(\left(V_{b}-V_{a}\right) / V_{b}\right) \times 100 \%\end{array}$} \\
\hline & Before exposed, $V_{b}$ & After exposed, $V_{a}$ & \\
\hline $\mathrm{ZnO} 0.02 \mathrm{M}$ : Urea $0.01 \mathrm{M}$ & $3.27 \mathrm{~V}$ & $1.77 \mathrm{~V}$ & 45.87 \\
\hline $\mathrm{ZnO} 0.01 \mathrm{M}$ : Urea $0.04 \mathrm{M}$ & $2.79 \mathrm{~V}$ & $1.19 \mathrm{~V}$ & 57.35 \\
\hline $\mathrm{ZnO} 0.01 \mathrm{M}$ : Urea $0.06 \mathrm{M}$ & $1.58 \mathrm{~V}$ & $0.53 \mathrm{~V}$ & 66.46 \\
\hline $\mathrm{ZnO} 0.01 \mathrm{M}$ : Urea $0.08 \mathrm{M}$ & $1.42 \mathrm{~V}$ & $0.21 \mathrm{~V}$ & 85.21 \\
\hline
\end{tabular}

with testing gases. When $\mathrm{ZnO}$ is exposed to $\mathrm{N}_{2}$ gas, the $\mathrm{N}$ molecules will be adsorbed on the $\mathrm{ZnO}$ surface and cause the change in chemical bonding and carrier concentration of $\mathrm{ZnO}: \mathrm{N}$. Molecules $\mathrm{N}$ arrived antact at the surface, so high concentration of $\left(\mathrm{N}_{2}\right)_{\mathrm{O}}$ centers will be observed at $\mathrm{Zn}$-rich conditions [3]. Generally, nitrogen exists in two forms, $(\mathrm{N})_{\mathrm{O}}$ which acts as an acceptor and $\left(\mathrm{N}_{2}\right)_{\mathrm{O}}$ which acts as donor in $\mathrm{ZnO}: \mathrm{N}$ [31]. $(\mathrm{N})_{\mathrm{O}}$ formed when $\mathrm{N}$ substitutes at $\mathrm{O}$ site, and $\left(\mathrm{N}_{2}\right)_{\mathrm{O}}$ formed when $\mathrm{N}_{2}$ substitute at $\mathrm{O}$ site also. Based on theoretical calculations, as-grown $\mathrm{ZnO}: \mathrm{N}$ films contain higher electron concentration than undoped $\mathrm{ZnO}$ because $\left(\mathrm{N}_{2}\right)_{\mathrm{O}}$ has a smaller formation energy than $(\mathrm{N})_{\mathrm{O}}$. That makes the resistance of film decreased when $\mathrm{ZnO}: \mathrm{N}$, exposed to $\mathrm{N}_{2}$ gas especially for $\mathrm{ZnO} 0.01 \mathrm{M}$ : Urea $0.08 \mathrm{M}$. The responses were increased by the conductivity of $\mathrm{ZnO}$ film. The result of $\mathrm{ZnO}$ film responses was detailed in Table 2 .

\section{Conclusion}

Porous $\mathrm{ZnO}$ nanoflakes were successfully synthesized at various molar concentrations of urea by using thermal immersion method. The analysis of FESEM images illustrates nanoflake formation on silicon substrate. The PL spectra show that the $\mathrm{ZnO}$ nanoflake has two emission bands: one is relatively strong UV emission centered about 390-400 nm, and the other is weaker emission observed in the greenyellow range of the visible spectrum with an emission peak about $600 \mathrm{~nm}$. The study of PL and $I-V$ measurements has demonstrated that an n-type $\mathrm{ZnO}$ doped with $\mathrm{N}(\mathrm{ZnO}: \mathrm{N})$ thin film is successfully fabricated by using simple immersion method. It is shown that, by controlling concentration of urea, we can obtain a good conductivity and $\mathrm{N}_{2}$ gas response of $\mathrm{ZnO}$ nanostructures. The minimum value of rectifying characteristic is observed at high concentration of urea in solution. It can be concluded that when high concentration of nitrogen atoms is introduced in the film, the p-type $\mathrm{ZnO}$ nanostructure behavior is observed.

\section{Acknowledgments}

The authors would like to thank the Universiti Teknologi MARA (UiTM), Malaysian Ministry of Higher Education (MOHE), and the Malaysian Government for their support and funding.

\section{References}

[1] R. Asahi, T. Morikawa, T. Ohwaki, K. Aoki, and Y. Taga, "Visible-light photocatalysis in nitrogen-doped titanium oxides," Science, vol. 293, no. 5528, pp. 269-271, 2001.
[2] K. Minegishi, Y. Koiwai, Y. Kikuchi, K. Yano, M. Kasuga, and A. Shimizu, "Growth of p-type zinc oxide films by chemical vapor deposition," Japanese Journal of Applied Physics, vol. 36, no. 11, pp. L1453-L1455, 1997.

[3] Y. Yan, S. B. Zhang, and S. T. Pantelides, "Control of doping by impurity chemical potentials: predictions for p-type Zno," Physical Review Letters, vol. 86, no. 25, pp. 5723-5726, 2001.

[4] A. Kaschner, U. Haboeck, M. Strassburg et al., "Nitrogen-related local vibrational modes in ZnO:N," Applied Physics Letters, vol. 80, no. 11, pp. 1909-1911, 2002.

[5] P. Thilakan, D. M. Radheep, K. Saravanakumar, and G. Sasikala, "Deposition and characterization of $\mathrm{ZnO}$ thin films by modified pulsed-spray pyrolysis," Semiconductor Science and Technology, vol. 24, no. 8, Article ID 085020, 2009.

[6] G. S. Wu, T. Xie, X. Y. Yuan et al., "Controlled synthesis of ZnO nanowires or nanotubes via sol-gel template process," Solid State Communications, vol. 134, no. 7, pp. 485-489, 2005.

[7] J. Z. Romeiro, F. C. Marinho, S. C. S. Lemos et al., "Urea-based synthesis of zinc oxide nanostructures at low temperature," Journal of Nanomaterials, vol. 2012, Article ID 427172, 7 pages, 2012.

[8] R. S. Gaikwad, R. S. Mane, B. N. Pawar et al., "Nitrogendoped $\mathrm{ZnO}$ shells: studies on optical transparency and electrical conductivity," Materials Research Bulletin, vol. 47, no. 5, pp. 1246-1250, 2012.

[9] J. D. Wright and N. A. J. M. Sommerdijk, Sol-Gel Materials: Chemistry and Applications, Taylor \& Francis Group, London, UK, 2001.

[10] D. Dollimore, J. A. France, B. W. Krupay, and R. Whitehead, "Kinetic aspects of the thermal decomposition of zinc carbonate," Thermochimica Acta, vol. 36, no. 3, pp. 343-349, 1980.

[11] J. P. Kar, M. H. Ham, S. W. Lee, and J. M. Myoung, "Fabrication of $\mathrm{ZnO}$ nanostructures of various dimensions using patterned substrates," Applied Surface Science, vol. 255, no. 7, pp. 40874092, 2009.

[12] L. Vayssieres, "Growth of arrayed nanorods and nanowires of $\mathrm{ZnO}$ from aqueous solutions," Advanced Materials, vol. 15, no. 5, pp. 464-466, 2003.

[13] L. Vayssieres, K. Keis, S.-E. Lindquist, and A. Hagfeldt, "Purpose-built anisotropie metal oxide material: 3D highly oriented microrod array of $\mathrm{ZnO}$," The Journal of Physical Chemistry B, vol. 105, no. 17, pp. 3350-3352, 2001.

[14] Z. Fan and J. G. Lu, "Zinc oxide nanostructures: synthesis and properties," Journal of Nanoscience and Nanotechnology, vol. 5, no. 10, pp. 1561-1573, 2005.

[15] E. Bacaksiz, S. Yilmaz, M. Parlak, A. Varilci, and M. Altunbaş, "Effects of annealing temperature on the structural and optical properties of $\mathrm{ZnO}$ hexagonal pyramids," Journal of Alloys and Compounds, vol. 478, no. 1-2, pp. 367-370, 2009.

[16] G. Kenanakis, M. Androulidaki, E. Koudoumas, C. Savvakis, and N. Katsarakis, "Photoluminescence of $\mathrm{ZnO}$ nanostructures 
grown by the aqueous chemical growth technique," Superlattices and Microstructures, vol. 42, no. 1-6, pp. 473-478, 2007.

[17] M. Ghosh and A. K. Raychaudhuri, "Shape transition in $\mathrm{ZnO}$ nanostructures and its effect on blue-green photoluminescence," Nanotechnology, vol. 19, no. 44, Article ID 445704, 2008.

[18] D. Behera and B. S. Acharya, "Nano-star formation in Aldoped $\mathrm{ZnO}$ thin film deposited by dip-dry method and its characterization using atomic force microscopy, electron probe microscopy, photoluminescence and laser Raman spectroscopy," Journal of Luminescence, vol. 128, no. 10, pp. 15771586, 2008.

[19] H.-C. Hsu, C.-S. Cheng, C.-C. Chang, S. Yang, C.-S. Chang, and W.-F. Hsieh, "Orientation-enhanced growth and optical properties of $\mathrm{ZnO}$ nanowires grown on porous silicon substrates," Nanotechnology, vol. 16, no. 2, pp. 297-301, 2005.

[20] S. A. Kamaruddin, K.-Y. Chan, M. Z. Sahdan, M. Rusop, and H. Saim, "ZnO microstructures and nanostructures prepared by sol-gel hydrothermal technique," Journal of Nanoscience and Nanotechnology, vol. 10, no. 9, pp. 5618-5622, 2010.

[21] Z. Khusaimi, S. Amizam, M. H. Mamat et al., "Controlled growth of zinc oxide nanorods by aqueous-solution method," Synthesis and Reactivity in Inorganic, Metal-Organic and NanoMetal Chemistry, vol. 40, no. 3, pp. 190-194, 2010.

[22] S. N. Bai, H. H. Tsai, and T. Y. Tseng, "Structural and optical properties of Al-doped $\mathrm{ZnO}$ nanowires synthesized by hydrothermal method," Thin Solid Films, vol. 516, no. 2-4, pp. 155-158, 2007.

[23] Z. Khusaimi, S. Amizam, H. A. Rafaie, M. H. Mamat, N. Abdullah, and M. Rusop, "A surface morphology study on the effect of annealing temperature to nanostructured $\mathrm{ZnO}$ and its reaction mechanism in solution method," AIP Conference Proceedings, vol. 1136, pp. 790-795, 2009.

[24] S. H. Lee, H. J. Lee, H. Goto, M.-W. Cho, and T. Yao, "Fabrication of porous $\mathrm{ZnO}$ nanostructures and morphology control," Physica Status Solidi (C), vol. 4, no. 5, pp. 1747-1750, 2007.

[25] D. Wang, Y. C. Liu, R. Mu et al., "The photoluminescence properties of $\mathrm{ZnO}: \mathrm{N}$ films fabricated by thermally oxidizing $\mathrm{Zn}_{3} \mathrm{~N}_{2}$ films using plasma-assisted metal-organic chemical vapour deposition," Journal of Physics: Condensed Matter, vol. 16, no. 25, pp. 4635-4642, 2004.

[26] V. R. Shinde, T. P. Gujar, C. D. Lokhande, R. S. Mane, and S.H. Han, "Mn doped and undoped $\mathrm{ZnO}$ films: a comparative structural, optical and electrical properties study," Materials Chemistry and Physics, vol. 96, no. 2-3, pp. 326-330, 2006.

[27] C. Wang, Z. Ji, J. Xi, J. Du, and Z. Ye, "Fabrication and characteristics of the low-resistive p-type $\mathrm{ZnO}$ thin films by DC reactive magnetron sputtering," Materials Letters, vol. 60, no. 7, pp. 912-914, 2006.

[28] A. Kobayashi, O. F. Sankey, and J. D. Dow, "Deep energy levels of defects in the wurtzite semiconductors AIN, CdS, CdSe, ZnS, and ZnO," Physical Review B, vol. 28, no. 2, pp. 946-956, 1983.

[29] F. Chaabouni, M. Abaab, and B. Rezig, "Metrological characteristics of ZNO oxygen sensor at room temperature," Sensors and Actuators B, vol. 100, no. 1-2, pp. 200-204, 2004.

[30] Y. Cao, P. Hu, W. Pan, Y. Huang, and D. Jia, "Methanal and xylene sensors based on $\mathrm{ZnO}$ nanoparticles and nanorods prepared by room-temperature solid-state chemical reaction," Sensors and Actuators B, vol. 134, no. 2, pp. 462-466, 2008.

[31] S. Limpijumnong, X. Li, S. H. Wei, and S. B. Zhang, "Substitutional diatomic molecules $\mathrm{NO}, \mathrm{NC}, \mathrm{CO}, \mathrm{N}_{2}$, and $\mathrm{O}_{2}$ : their vibrational frequencies and effects on $\mathrm{p}$ doping of $\mathrm{ZnO}$," Applied Physics Letters, vol. 86, no. 21, Article ID 211910, 3 pages, 2005. 

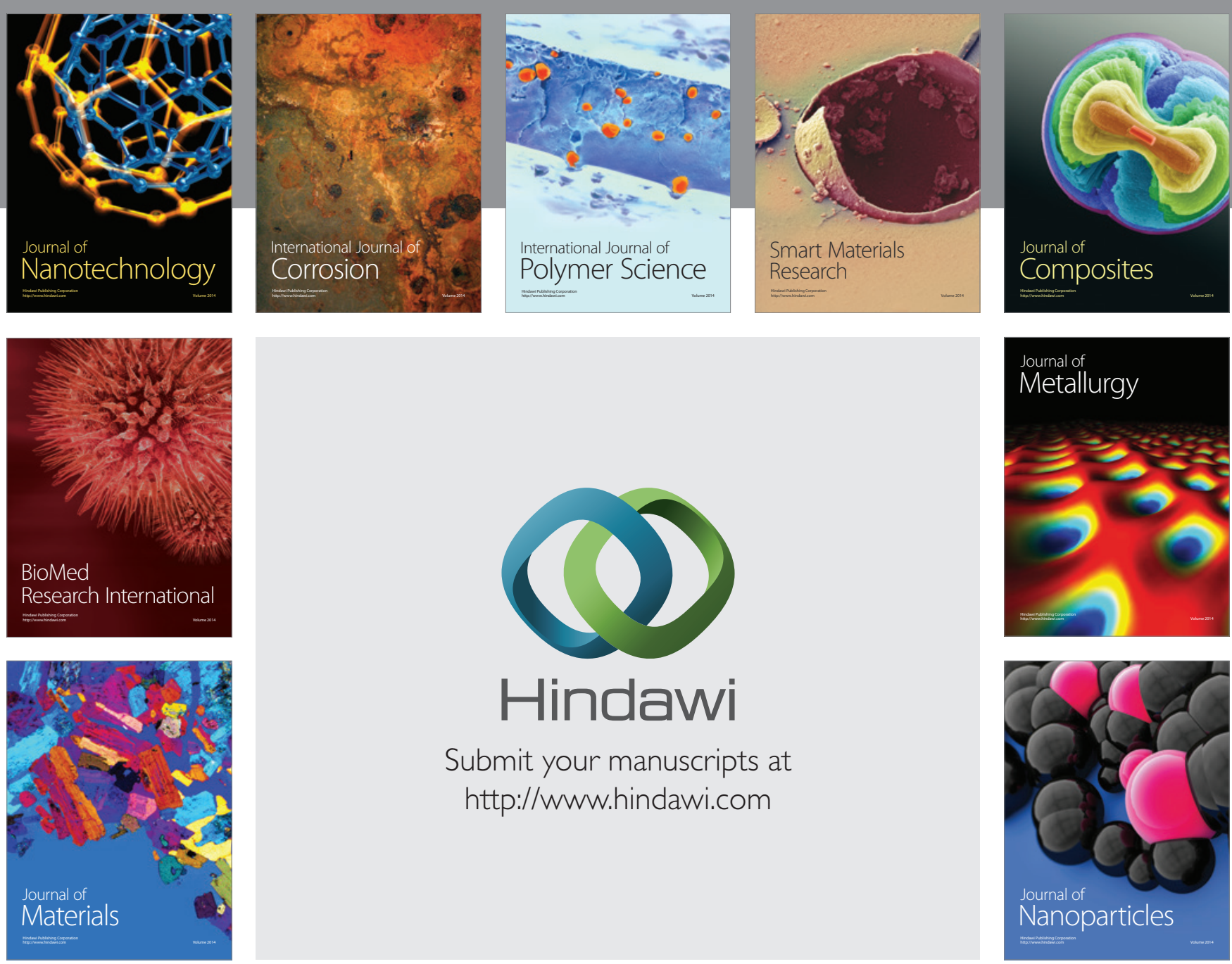

Submit your manuscripts at http://www.hindawi.com
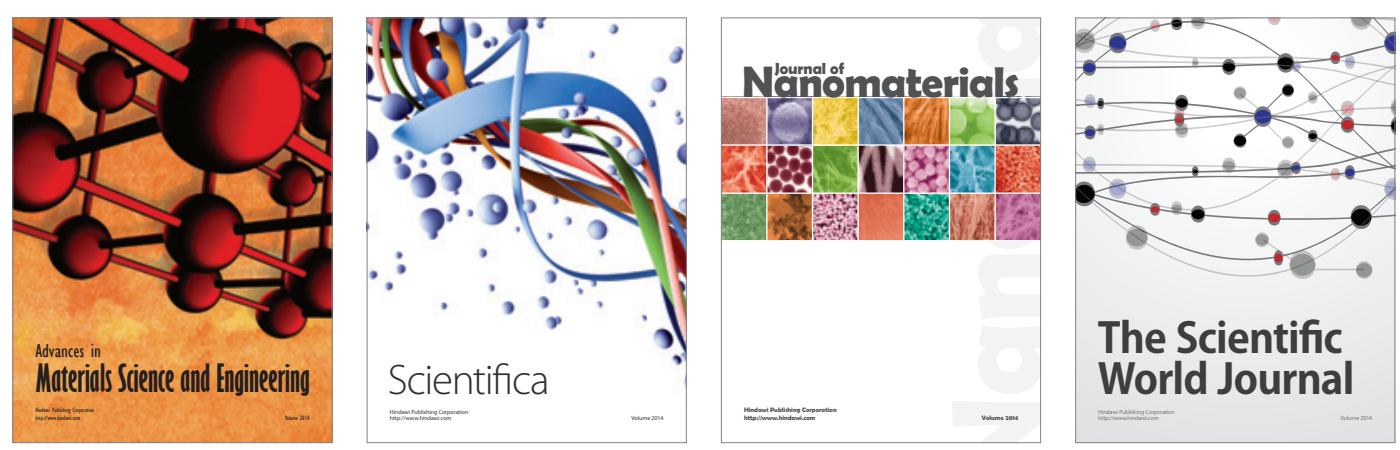

\section{The Scientific World Journal}
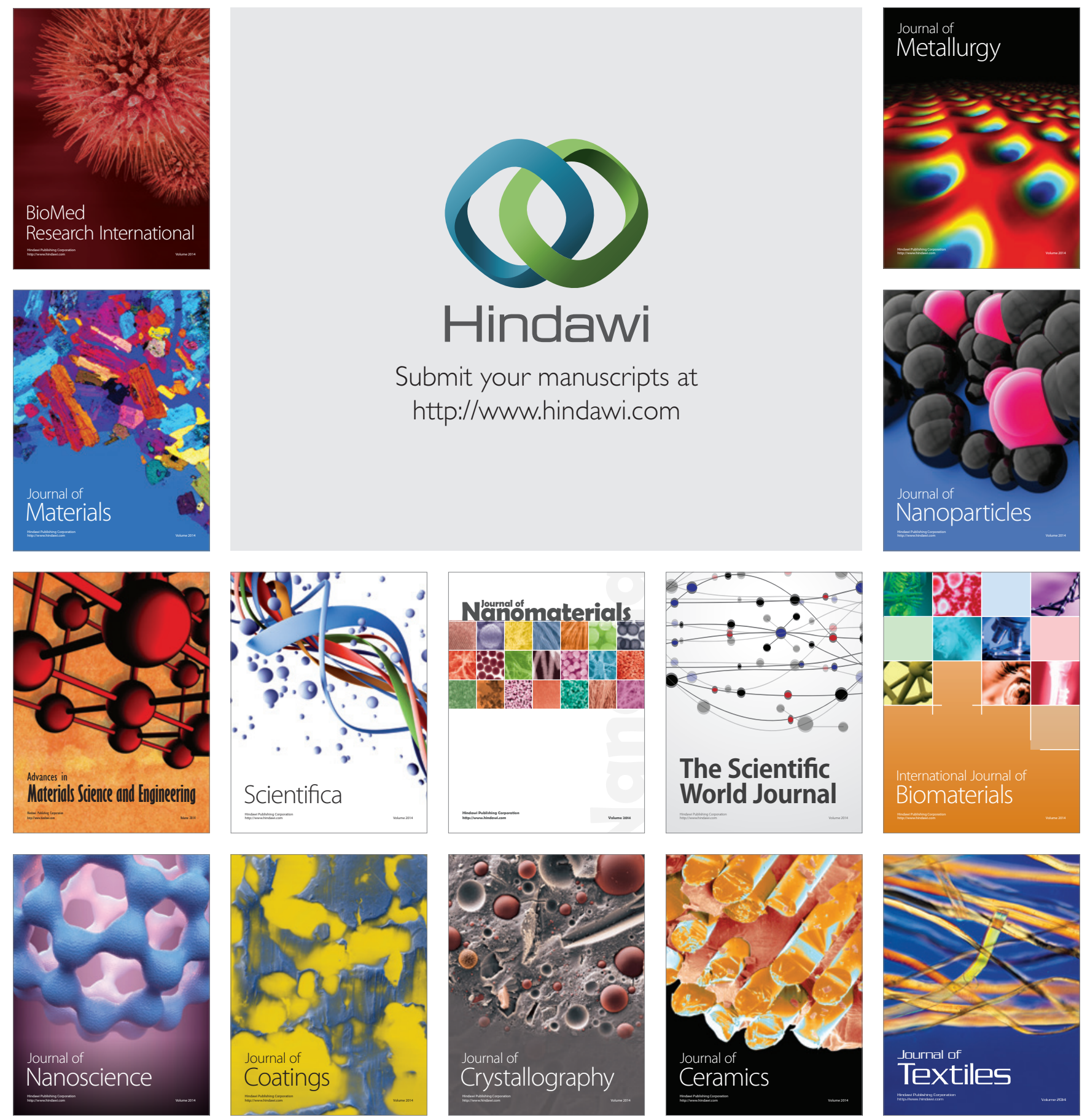